\title{
Infective juveniles of entomopathogenic nematodes (Steinernema and Heterorhabditis) secrete ascarosides and respond to interspecific dispersal signals
}

\author{
Cathryn J. Hartley ${ }^{1}$, Peter E. Lillis ${ }^{1}$, Rebecca A. Owens, Christine T. Griffin* \\ Department of Biology, Maynooth University, Maynooth, County Kildare, Ireland
}

\section{A R T I C L E I N F O}

\section{Keywords:}

Pheromone

Biocontrol

Biological pest control

Interspecific communication

Metabolomics

\begin{abstract}
A B S T R A C T
Ascarosides are a modular series of signalling molecules that are widely conserved in nematodes where they function as pheromones with both behavioural and developmental effects. Here we show that the developmentally arrested infective juvenile (IJ) stage of entomopathogenic nematodes (EPN) secrete ascarosides into the surrounding medium. The exometabolome of Steinernema carpocapsae and Heterorhabditis megidis was examined at $0,1,7$ and 21 days of storage. The concentration of several ascarosides (ascr\#11, ascr\#9, ascr\#12, ascr\#1 and ascr\#14 for both species, plus ascr\#10 for $H$. megidis) showed a progressive increase over this period, while the concentration of longer chain ascarosides increased up to day 7, with an apparent decline thereafter. Ascr \#9 was the main ascaroside produced by both species. Similar ascarosides were found over a 7-day period for Steinernema longicaudum and S. feltiae. Ascaroside blends have previously been shown to promote nematode dispersal. $S$. carpocapsae and $H$. megidis IJs were stored for up to 12 weeks and assayed at intervals. IJs where exometabolome was allowed to accumulate showed higher dispersal rates than those where water was changed frequently, indicating that IJ exometabolome maintained high dispersal. Infectivity was not affected. IJ exometabolome accumulated over 7 days promoted dispersal of freshly harvested IJs, both of their own and other EPN species. Similarly, extracts of nematode-infected cadavers promoted dispersal of con- and heterospecific IJs. Thus, IJs are encouraged to disperse from a source cadaver or from other crowded conditions by public information cues, a finding that may have application in enhancing biocontrol. However, the complexity of the ascaroside blend produced by IJs suggests that it may have ecological functions other than dispersal.
\end{abstract}

\section{Introduction}

Ascarosides are a family of small signalling molecules with both behavioural and developmental effects that are widely conserved in nematodes (Edison, 2009; Butcher, 2017). They are composed of the dideoxy sugar, ascarylose, covalently linked to a fatty-acid side chain. Variation in structure and length of the fatty acid side chain, together with various modifications of the ascarylose, results in a modular system with great potential variety (Butcher, 2017; von Reuss, 2018). The signalling role of ascarosides was first recognised when they were identified as constituents of the Caenorhabidits elegans dauer pheromone (Jeong et al., 2005; Butcher et al., 2007; Srinivasan et al., 2008). Ascaroside synthesis and signalling has since been identified in several phylogenetically distant nematode taxa apart from C. elegans, including entomopathogenic nematodes (Choe et al., 2012; Noguez et al., 2012;
Butcher, 2017).

Entomopathogenic nematodes (EPN), principally Steinernema spp and Heterorhabditis spp., are a clade of "beneficial" nematodes with a wide natural distribution in soils and other cryptic habitats. The infective juvenile (IJ) - a stage analogous to the $C$. elegans dauer juvenile is a non-feeding, stress resistant stage that actively seeks out insect hosts. IJs invade insects which they rapidly kill with the aid of their symbiotic bacteria. IJs resume development ("recover") and multiply within the host cadaver, and eventually a new generation of IJs emerges and disperses from the spent resource to seek out fresh hosts to infect. As a result of their active host-seeking and rapid mortality for insects, several EPN species have been commercialised for use as a biological insecticide. For this purpose, they are produced in large scale bioreactors and IJs are applied to crops, normally in liquid suspension. Noguez et al. (2012) identified an ascaroside produced by

\footnotetext{
* Corresponding author.

E-mail address: Christine.griffin@mu.ie (C.T. Griffin).

${ }^{1}$ Joint first authors.
} 
Heterorhabditis bacteriophora at high densities (such as those found within a host) that prevented IJs from resuming development. Two other studies have reported ascaroside production and/or function in EPN (Choe et al. 2012; Kaplan et al., 2012). As part of a broader survey of free-living and parasitic nematodes, Choe et al. (2012) identified several ascarosides produced by $H$. bacteriophora adults and by adult and IJ stages of three Steinernema species. Limited functional analysis included in that study showed that Steinernema glaseri males were retained by a selection of ascarosides in single-chemical assays (Choe et al., 2012).

Kaplan et al. (2012) focussed on responses of IJs to ascarosides. Since IJs are the active ingredient of biopesticides, their behaviour is of considerable applied interest and has been intensively researched for several decades (see reviews by Lewis et al. (2006) and Griffin (2015)). Kaplan et al. (2012) studied the effects of ascarosides on the dispersal of IJs. Firstly, they found that C. elegans dispersal signal (a blend of ascarosides) promoted dispersal of Steinernema feltiae IJs (and also of J2 of the plant parasite Meloidogyne spp.) leading to the conclusion that interspecific nematode signals regulate dispersal. Secondly, in a more ecologically relevant investigation, they showed that extract of insect cadavers infected by $S$. feltiae promoted dispersal of $S$. feltiae IJs and that ascarosides (especially ascr\#9) accumulated in the cadaver, with accumulation highest immediately prior to the dispersal of IJs from the cadavers. The hypothesis that ascarosides produced within the host cadaver are part of a dispersal pheromone for $S$. feltiae IJs was supported by dispersal assays of fractionated cadaver extract and synthetic ascarosides. Two ascarosides (ascr\#9 and ascr\#11) were detected in the ascaroside-rich fraction of cadaver extract, and synthetic versions of either of these at physiological concentrations stimulated dispersal - but only when combined with the other two fractions of natural cadaver extract (Kaplan et al., 2012). Finally, ascarosides were detected in cadavers infected by three other species of Steinernema and by three species of Heterorhabditis. All extracts contained ascr\#9, suggesting that ascr\#9 may be used by a broad range of EPN as part of their dispersal blends, while ascr\#11 was found in all species of Steinernema, but not in Heterorhabditis, suggesting that ascr\#11 might be specific for Steinernema (Kaplan et al., 2012).

Here we investigate the secretion by IJs of ascarosides and/or other behaviour-affecting substances, and the responses of IJs to dispersal signals derived from nematode-infected cadavers and from IJs. EPN are routinely stored in aqueous suspension both in the laboratory and commercially prior to formulation, making it important to resolve any effect this may have on behaviour and efficacy. We test three hypotheses: (1) that IJs continue to secrete ascarosides beyond the $6 \mathrm{~h}$ reported by Choe et al. (2012); (2) that exometabolome (ascarosides and/or other chemicals secreted by IJs) will accumulate in the water in which they are stored and affect the behaviour both of the stored IJs and of other IJs exposed to the exometabolome, and (3) that dispersal cues derived from IJs and from infected host cadavers are not species specific, but instead are public information, indicating crowding. This hypothesis that interspecific nematode signals regulate dispersal is based on the findings of Kaplan et al. (2012). If cadaver macerate or extracts prepared from cadavers are used to promote success of EPN in biocontrol as has been suggested (Wu et al., 2018; Oliveira-Hofman et al., 2019), it would be of obvious commercial benefit if preparations made from insects infected with one EPN species would also promote dispersal of other EPN species.

To test our hypotheses, we store IJs in water for up to 21 days and identify secreted ascarosides in the exometabolome. We then test whether preventing the accumulation of exometabolome during longterm storage by frequently removing and replacing the water affects the behaviour (dispersal and virulence) of the stored IJs themselves, relative to IJs where the water is not changed. We further test whether water in which IJs were stored for a week (IJ-conditioned water) stimulates dispersal when applied to other nematodes. Finally, we explore whether the dispersal signal of IJ-conditioned water and of nematode- infected cadavers is species-specific by assaying preparations of each of four EPN species on each of the other species. We use members of both EPN genera, Heterorhabditis megidis and three species of Steinernema ( $S$. carpocapsae, S. feltiae and S. longicaudum). Each of the three Steinernema species belongs to a different clade of the genus (clades II, III and V, respectively) (Nadler et al., 2006).

\section{Materials and methods}

\subsection{Nematode culture and storage}

The nematodes used were $S$. longicaudum CB2B, $S$. carpocapsae All, S. feltiae 4CFMO and $H$. megidis UK211. Nematodes were cultured in last instar larvae of Galleria mellonella (Mealworm Company, Sheffield, UK) using standard procedures (Woodring and Kaya, 1988), at $20^{\circ} \mathrm{C}\left(27^{\circ} \mathrm{C}\right.$ for $S$. longicaudum), with an inoculum density of $100 \mathrm{IJ} /$ insect. Cadavers were placed in White traps and IJs were harvested daily. IJs that emerged 2-5 days after emergence began were pooled, rinsed three times by sedimentation, and stored in sterile tap water in $50 \mathrm{ml}$ aliquots in lidded plastic dishes ( $9 \mathrm{~cm}$ diam.).

\subsection{Chemical profiling of IJ-conditioned water}

Freshly harvested IJs were washed by sedimentation successively in the following: tap water; 50:50 tap water: milliQ water, and finally milliQ water. The final wash water was retained and used to control for residual ascarosides produced within the cadaver (time 0). IJs (5000/ $\mathrm{ml}$ ) were stored in milliQ water at $20^{\circ} \mathrm{C}$. After 1 or 7 (and 21 days in the case of $S$. carpocapsae and $H$. megidis), conditioned water containing IJ exometabolome was separated from IJs by sedimentation followed by filtration through a $0.22 \mu \mathrm{m}$ filter. All filters and tubes were rinsed with milliQ water prior to use. Samples $(20 \mathrm{ml})$ were frozen at $-20^{\circ} \mathrm{C}$ overnight and were transferred to liquid nitrogen and lyophilised. Lyophilised material was stored at $4{ }^{\circ} \mathrm{C}$ until mass spectrometry (MS) analysis. Samples were resuspended in HPLC-grade methanol $(1 \mathrm{ml})$ and placed in a sonication bath for $2 \mathrm{~min}$. Samples were dried using a vacuum concentrator and resuspended in $100 \mu \mathrm{l}$ methanol. Samples were prepared for LC-MS/MS analysis by mixing $1: 1$ with $0.1 \%$ formic acid. Samples were analysed using a Dionex Ultimate 3000 RSLCnano coupled to a Thermo Q-Exactive mass spectrometer. A $10 \mathrm{~min}$ method was designed which included a 5-70\% B gradient (A: $0.1 \%$ formic acid, B: $0.1 \%$ formic acid in acetonitrile) and $5 \mu \mathrm{l}$ of sample (equivalent to the secretion of 5000 IJs) was injected onto a Thermo Hypersil Gold aQ polar-C18 column $(100 \times 2.1 \mathrm{~mm}, 1.9 \mu \mathrm{m}$ particles $)$. Samples were analysed in negative mode, using a Top3 MS/MS method (NCE $40 \mathrm{eV}$ ). For each species, there were three biological replicates (each prepared from a different culture batch of nematodes). For each ascaroside detected, a regression of relative abundance on time was performed.

\subsection{Effect of IJ conditioned water on dispersal of IJs}

IJ suspension (5000 IJs/ml) was stored at $20^{\circ} \mathrm{C}\left(27^{\circ} \mathrm{C}\right.$ for $S$. longicaudum) for 7 days. Following this, IJs were removed by sedimentation and the supernatant was filtered through a $0.2 \mu \mathrm{m}$ syringe filter (Acrodisc). The filtered exudate was used to test the dispersal of freshly harvested IJs ( $48 \mathrm{~h}$ since harvest). IJs were concentrated by sedimentation immediately prior to use in the assay. Approximately $100-200 \mathrm{IJs}$ in $5 \mu \mathrm{l}$ water were applied to the centre of an agar plate ( $2 \%$ bacto agar in $5.5 \mathrm{~cm}$ Petri dish) followed by immediate application of $2 \mu \mathrm{l}$ of IJ-conditioned water (equivalent to the secretion of $10 \mathrm{IJs}$ ) or water only (controls). A circular glass coverslip (19 mm diameter) was placed over the suspension, delimiting a central application zone. Plates were incubated at $20{ }^{\circ} \mathrm{C}$ (or $27{ }^{\circ} \mathrm{C}$ for $S$. longicaudum) for $10 \mathrm{~min}$. IJs remaining under the coverslip were recorded as not dispersed and those migrating onto the open agar surface were recorded as dispersed. Counting was done with the aid of a dissecting microscope. There were 


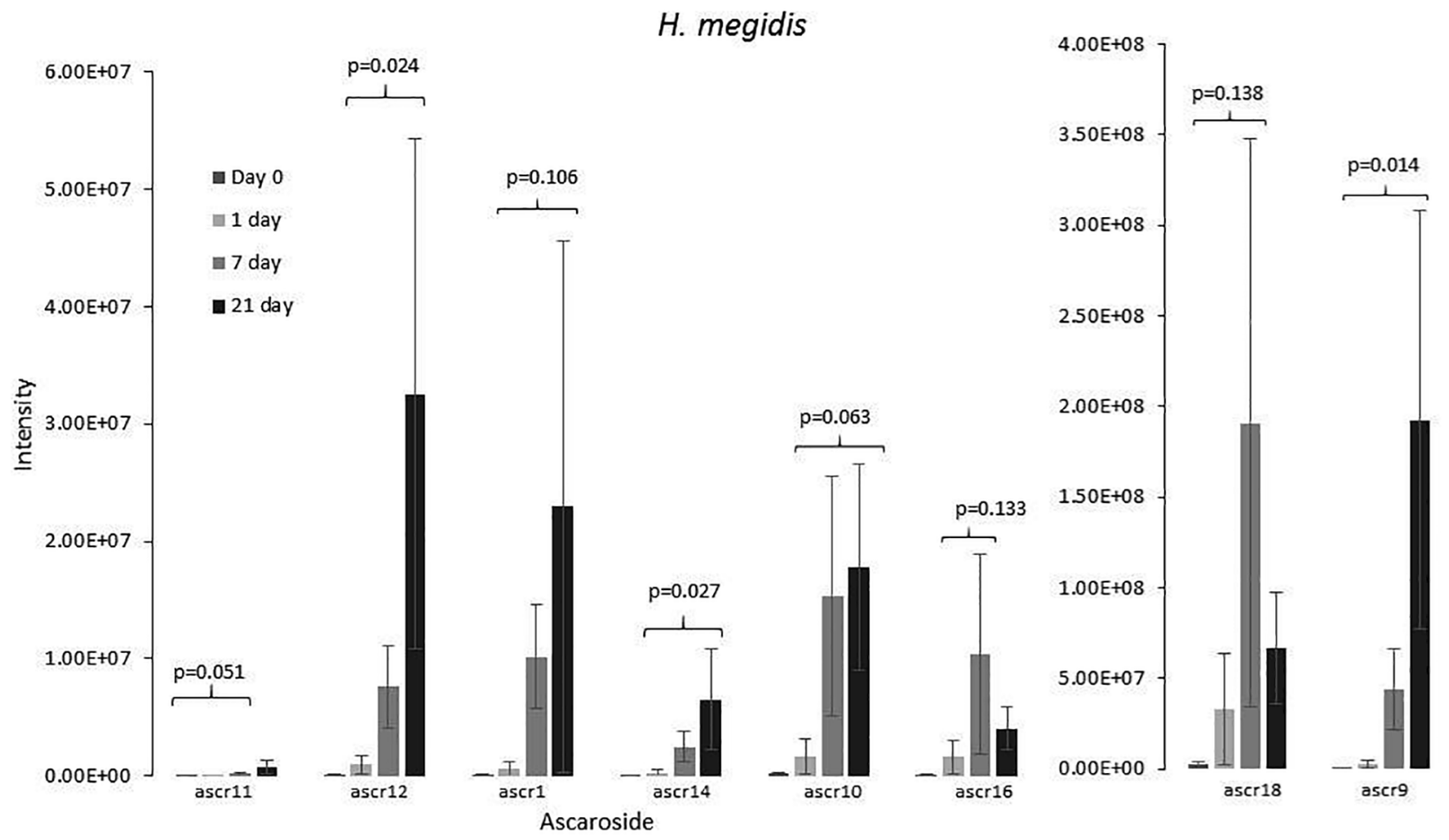

\section{S. carpocapsae}
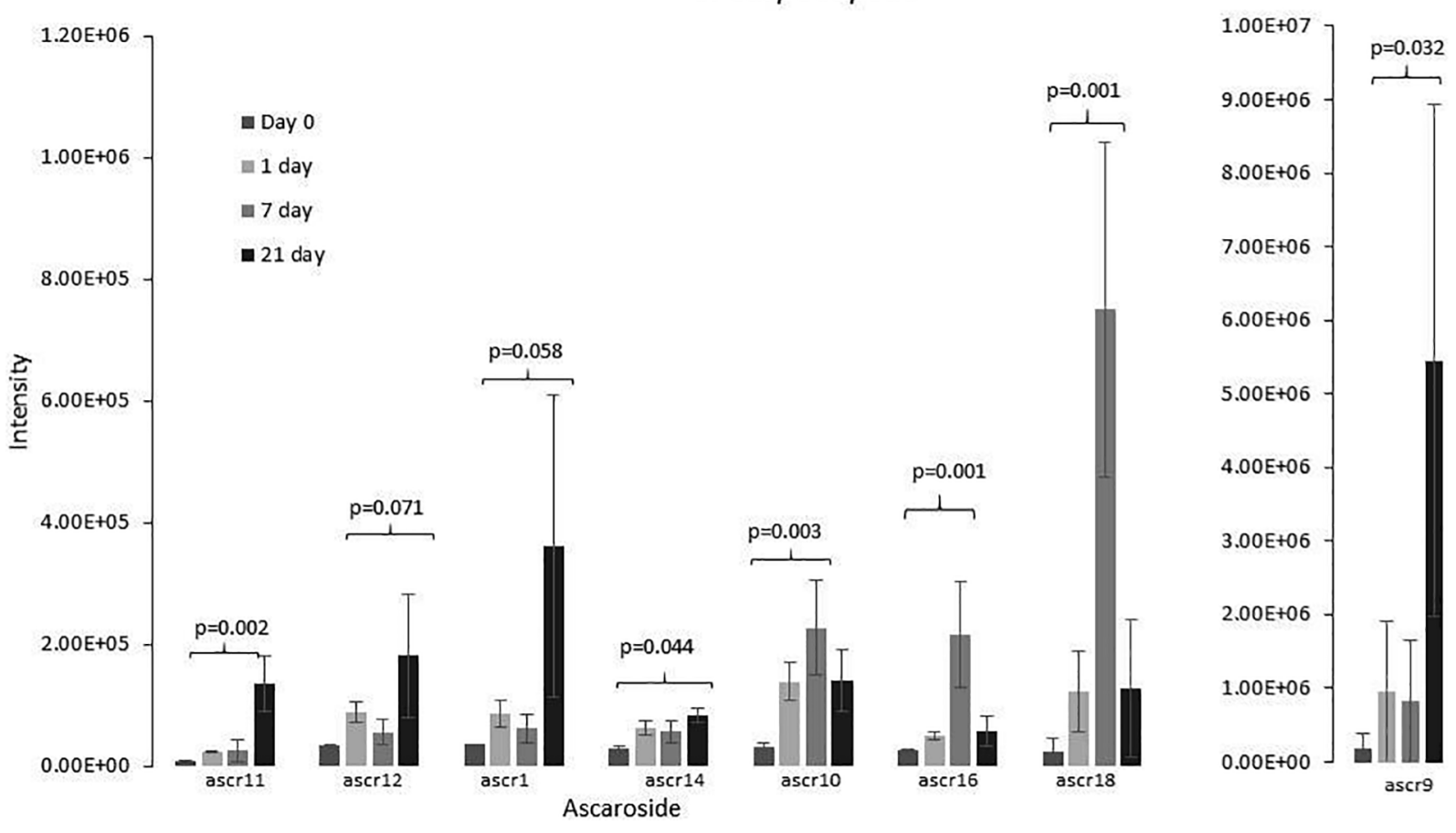

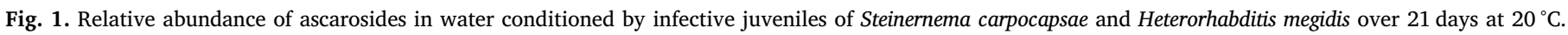

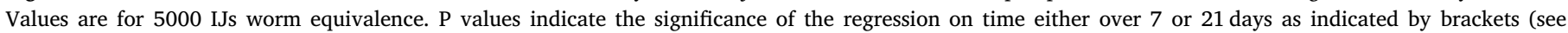
Supplementary Table 1).

two experiments. In the first, IJs of each species were tested with water conditioned by IJs of their own species. This experiment was run three times with independent preparations of IJ conditioned water and test IJs, and 10 assay plates per treatment in each experiment. Data were analysed for each species using GLM with treatment as a fixed factor and experiment as a random factor. In the second experiment, IJs of each species were tested with water conditioned by IJs of their own and the other three species. This experiment was run four times, once for each test species, with freshly prepared IJ-conditioned water of all four species and 10 assay plates per treatment in each experiment.

2.4. Influence of replacing storage water on IJ dispersal and virulence (H. Megidis and S. carpocapsae)

IJ suspension $(1000 \mathrm{IJ} / \mathrm{ml})$ was stored at $20{ }^{\circ} \mathrm{C}$, and the water was either changed at intervals (to limit the accumulation of 


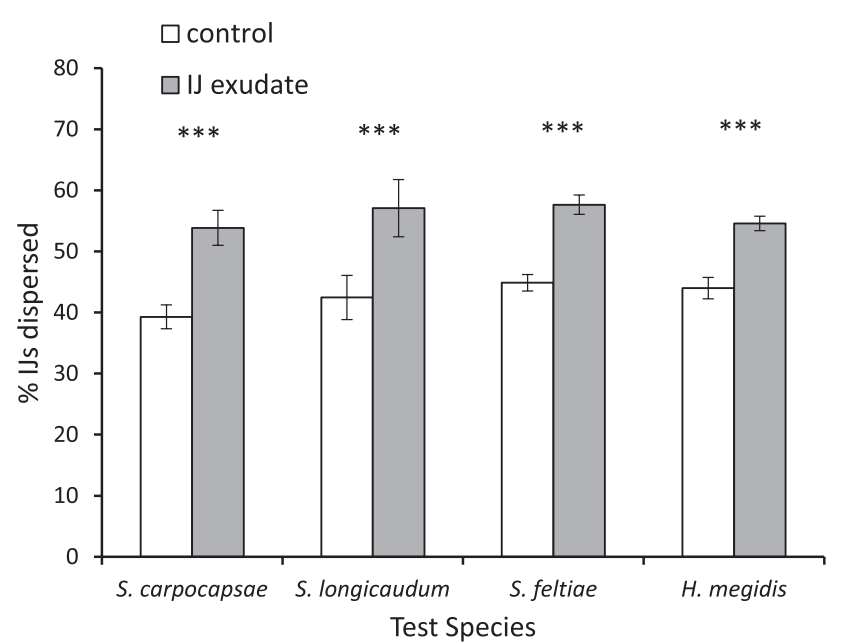

Fig. 2. Percentage (mean \pm SE) of IJs dispersing from $2 \mu l$ water conditioned with conspecific IJs (5000 IJ/ml for 7 days; i.e. $10 \mathrm{IJs}$ worm equivalence). Mean of three independent experiments. Within species, $* * *=\mathrm{P}<0.001$.

exometabolome) or left unchanged. To change the water, the contents of a dish were transferred to a $50 \mathrm{ml}$ centrifuge tube and IJs were allowed to sediment. The water was then decanted and replaced with fresh sterile tap water and the suspension was returned to the dish. For the unchanged treatment (control), IJs were allowed to sediment in a centrifuge tube which was then inverted to resuspend the IJs in the original water before returning to the storage dish. The dispersal and virulence of IJs was assayed at intervals during storage. IJs for assay were collected immediately after the treatment (resuspension or change of water). Dispersal was assayed as described above. Virulence was assessed against mealworms, Tenebrio molitor, in a close-contact assay. Wells of a 24-well cell culture plate were lined with moistened coconut coir and $10 \mathrm{IJs}$ in $10 \mu \mathrm{l}$ were added to 12 of the wells in each plate, while the other 12 wells received $10 \mu \mathrm{l}$ tap water only and served as controls. A T. molitor larva was added to each well. Plates were closed, sealed with Parafilm and incubated for 4 days in the dark at $20{ }^{\circ} \mathrm{C}$. One assay plate was used per replicate storage dish. Mortality in the nematode treatments was corrected for control mortality using Abbott's formula.

The experiment was run twice with independent batches of nematodes for each of $H$. megidis and $S$. carpocapsae and five storage dishes per treatment in each experiment. In the first experiment IJs were stored at $20^{\circ} \mathrm{C}$ (which is within the optimum temperature range for activity of these species). Water was replaced every 2-3 days and assays were conducted at time 0 and after 1, 2, 3, 4 and 5 weeks. In the second experiment IJs were stored at $9^{\circ} \mathrm{C}$ (a temperature below the optimum temperature range for activity, with prolonged longevity). Water was replaced every 7 days and assays were conducted at time 0 and after 3 , 6, 9 and 12 weeks. All assays were at $20^{\circ} \mathrm{C}$. Data were subjected to regression analysis with time as a continuous variable and treatment as categorical.

\subsection{Effect of cadaver extract on dispersal}

Cadaver extract was prepared using infected wax moths 1-2 days after IJ emergence had commenced. Cadavers were punctured several times using a sterile needle in $1.5 \mathrm{ml}$ Eppendorf tubes ( 2 per tube), then $500 \mu \mathrm{l}$ of sterile distilled $\mathrm{H}_{2} \mathrm{O}$ was added to the tube which was vortexed thoroughly to liberate the contents of the cadavers. Tubes were centrifuged at $800 \mathrm{~g}$ for $10 \mathrm{~min}$. The supernatant was centrifuged a second time $(800 \mathrm{~g}, 10 \mathrm{~min}$ ) and the resulting supernatant (equivalent to 4 cadavers $/ \mathrm{ml}$ ) was used to test the dispersal of freshly harvested IJs as described above, using $2 \mu \mathrm{l}$ of cadaver extract (equivalent to 0.008 cadavers). There were two experiments. In the first, IJs of each species were tested with their own cadaver extract. In the second, IJs of each of the four nematode species were assayed with extract from cadavers infected with each of the four species. This experiment was conducted once for each of the four nematode species, with cadaver extract freshly prepared for each experiment. There were 10 replicate assay plates for each treatment in each experiment. For intraspecific comparison of cadaver extract with control, two-sample $t$ tests were used. In the crossspecies cadaver experiments, a one-way ANOVA was followed by Tukey's post hoc test when $\mathrm{P}<0.05$ to identify where significant differences occurred.

\section{Results}

\subsection{Identification of ascarosides in IJ-conditioned water}

The exometabolome of $S$. carpocapsae and $H$. megidis IJs was analysed for up to 21 days of storage. The relative concentration of several ascarosides (ascr\#11, ascr\#9, ascr\#12, ascr\#1 and ascr\#14, and ascr\#10 for $H$. megidis) showed a progressive increase over this period, and the regression of relative abundance on time was significant $(\mathrm{P}<0.05)$ or approaching significance $(\mathrm{P}<0.10)$ in each case (Fig. 1; Supplementary Fig. 1, Supplementary Table 1). The concentration of longer chain ascarosides ascr\#16 and ascr\#18, and ascr\#10 in the case of $S$. carpocapsae) increased up to day 7, followed by an apparent decline between day 7 and day 21 (Fig. 1). Ascr \#9 was the main ascaroside detected for both species, while ascr\#18 was also prominent in the H. megidis exometabolome (Fig. 1). Seven-day exometabolome of IJs of two other species, $S$. longicaudum and $S$. feltiae showed a similar profile to that of $S$. carpocapsae, with ascr $\# 9$ as the main signature and trace amounts of ascr $\# 11$, ascr\#12, ascr\#1, ascr\#14 ascr\#16 and ascr\#18.

\subsection{IJ dispersal is promoted by exposure to water conditioned by conspecific and heterospecific IJs}

Water conditioned with IJs $(5000 / \mathrm{ml})$ for 7 days stimulated dispersal of conspecific IJs relative to the control and the difference was significant for each of the four species tested $\left(H\right.$. megidis: $\mathrm{F}_{1,56}=31.41$, $\mathrm{P}<0.001 ;$ S. carpocapsae: $\mathrm{F}_{1,56}=25.39, \mathrm{P}<0.001 ;$ S. feltiae: $\mathrm{F}_{1,56}=43.93, \mathrm{P}<0.001 ;$ S. longicaudum: $\mathrm{F}_{1,56}=51.26, \mathrm{P}<0.001$ ) (Fig. 2). The storage concentration of $5000 \mathrm{IJs} / \mathrm{ml}$ was chosen based on the results of preliminary assays with concentrations ranging from 500 to $5000 \mathrm{IJs} / \mathrm{ml}$. The minimum storage concentration for which dispersal differed significantly from the control ranged from 500 (S. feltiae) to 5000 ( $H$. megidis), with the other two species showing intermediate levels of 1000 (S. longicaudum) or 2000 (S. carpocapsae) IJs/ml (data not shown). The promotion of IJ dispersal by IJ exudate was not species-specific (Fig. 3). For each test species, there was a significant difference due to treatment $\left(H\right.$. megidis: $\mathrm{F}_{4,45}=18.34, \mathrm{P}<0.001 ; S$. carpocapsae: $\mathrm{F}_{4,45}=4.69, \quad \mathrm{P}=0.003 ; \quad S . \quad$ feltiae: $\quad \mathrm{F}_{4,45}=11.65$, $\mathrm{P}<0.001 ; S$. longicaudum: $\mathrm{F}_{4,45}=5.05, \mathrm{P}=0.002$ ). In general, the percentage of IJs dispersing differed to that in the control irrespective of the species used to condition the water (Tukey test) (Fig. 3). For each of the three Steinernema species, there was no difference in the percentage of IJs dispersing due to the species used to condition the water. While there were significant differences in the response of $H$. megidis to the various exudates, the proportion of IJs dispersing in the presence of exudate from Steinernema spp was at least as high as in response to exudate of conspecific IJs (Fig. 3).

\subsection{Replacing water during storage impacts dispersal but not virulence of stored IJs}

The dispersal rate of both $H$. megidis and $S$. carpocapsae IJs declined over time and the effect of time was highly significant $(\mathrm{P}<0.001)$ for both species at both storage temperatures (Fig. 4). There was a 


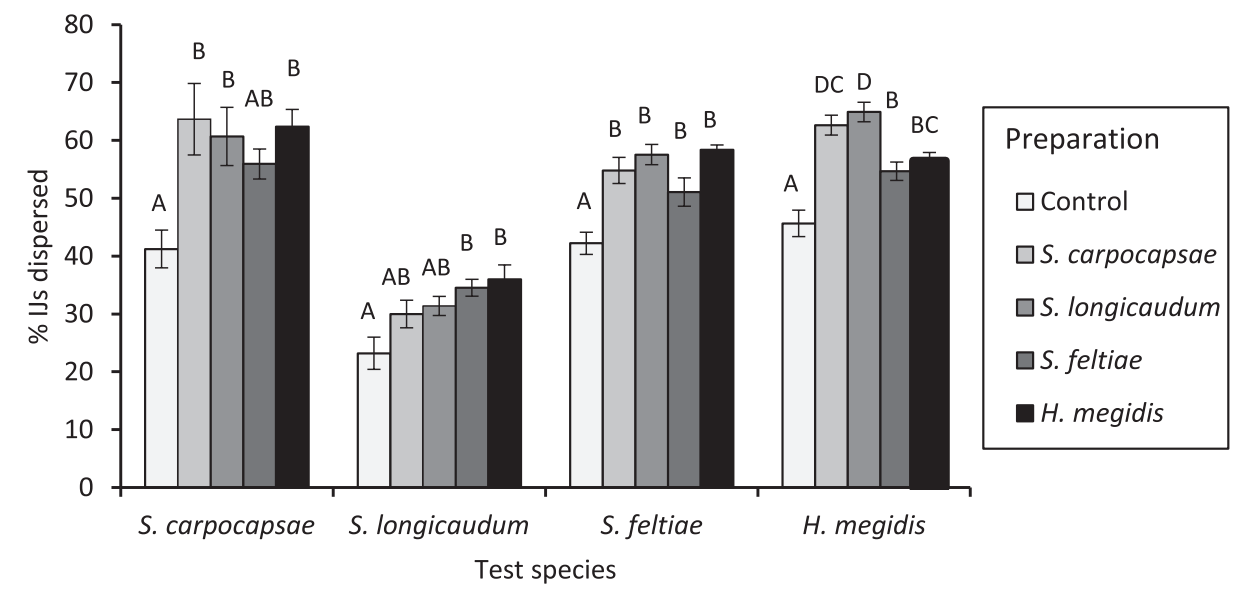

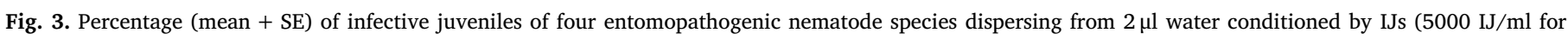
7 days; i.e. 10 IJs worm equivalence) of each of the four species. Within test species, bars which do not share a letter differ significantly.

significant interaction between storage treatment and storage duration for both species when stored at $20^{\circ} \mathrm{C}\left(H\right.$. megidis: $\mathrm{F}_{1,116}=6.29$, $\mathrm{P}=0.014 ;$ S. carpocapsae: $\mathrm{F}_{1,116}=4.85, \mathrm{P}=0.030$ ) and for $S$. carpocapsae stored at $9^{\circ} \mathrm{C}\left(\mathrm{F}_{1,96}=24.57, \mathrm{P}<0.001\right)$. At later time points, IJs where the storage water was changed regularly dispersed less than IJs where the water was not changed (Fig. 4). There was no effect of storage treatment on virulence for either species stored at either 9 or $20^{\circ} \mathrm{C}(\mathrm{P}>0.05$; data not shown).

\subsection{Effect of infected cadaver extract on dispersal is not species-specific}

In the cadaver extract assay, treatment had a significant effect on
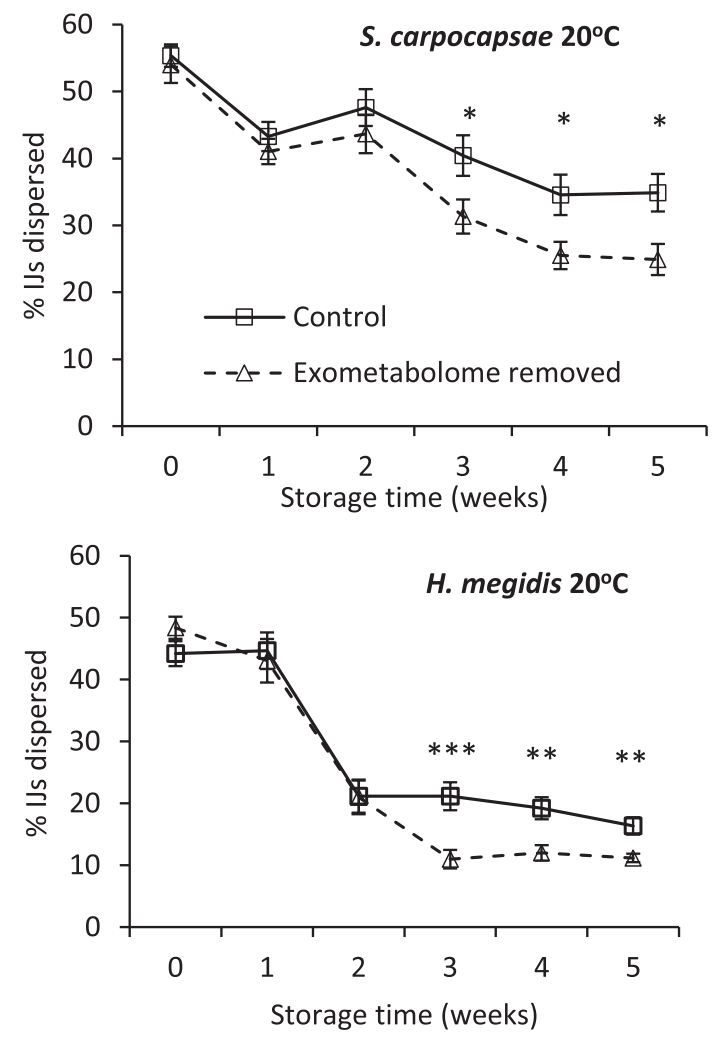

dispersal of IJs of each of the four species tested (H. megidis: $\mathrm{F}_{4,45}=60.94, \mathrm{P}<0.001 ;$ S. carpocapsae: $\mathrm{F}_{4,45}=53.01, \mathrm{P}<0.001 ; S$. feltiae: $\mathrm{F}_{4,45}=10.32, \quad \mathrm{P}<0.001 ; \quad S$. longicaudum: $\mathrm{F}_{4,45}=23.62$, $\mathrm{P}<0.001$ ). For each species, the percentage of IJs dispersing in the presence of cadaver extract was higher than in the control, but there was no difference between the four cadaver extracts (Tukey test) (Fig. 5).

\section{Discussion}

Here we show that ascarosides accumulate in the water in which IJs of Steinernema and Heterorhabditis are stored, and this accumulation
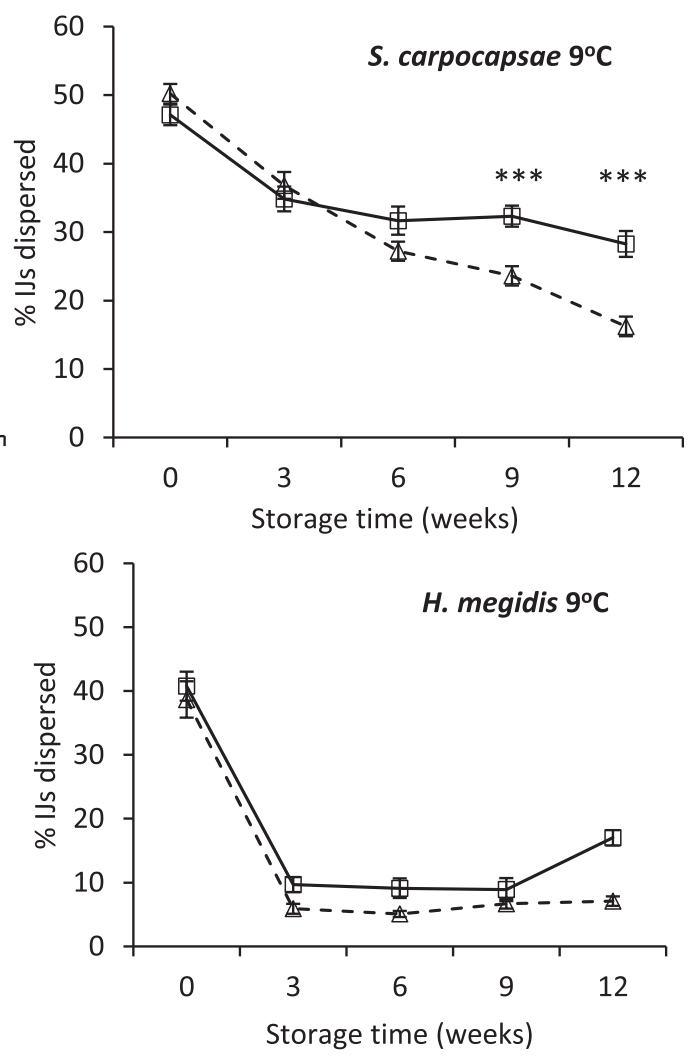

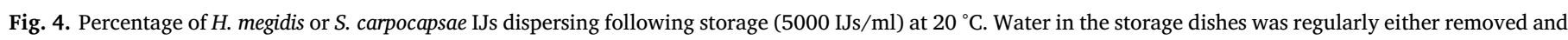

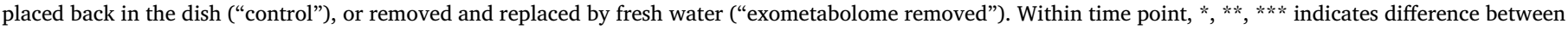
treatments significant at $\mathrm{P}<0.05, \mathrm{P}<0.01$ or $\mathrm{P}<0.001$. 
Cadaver extract

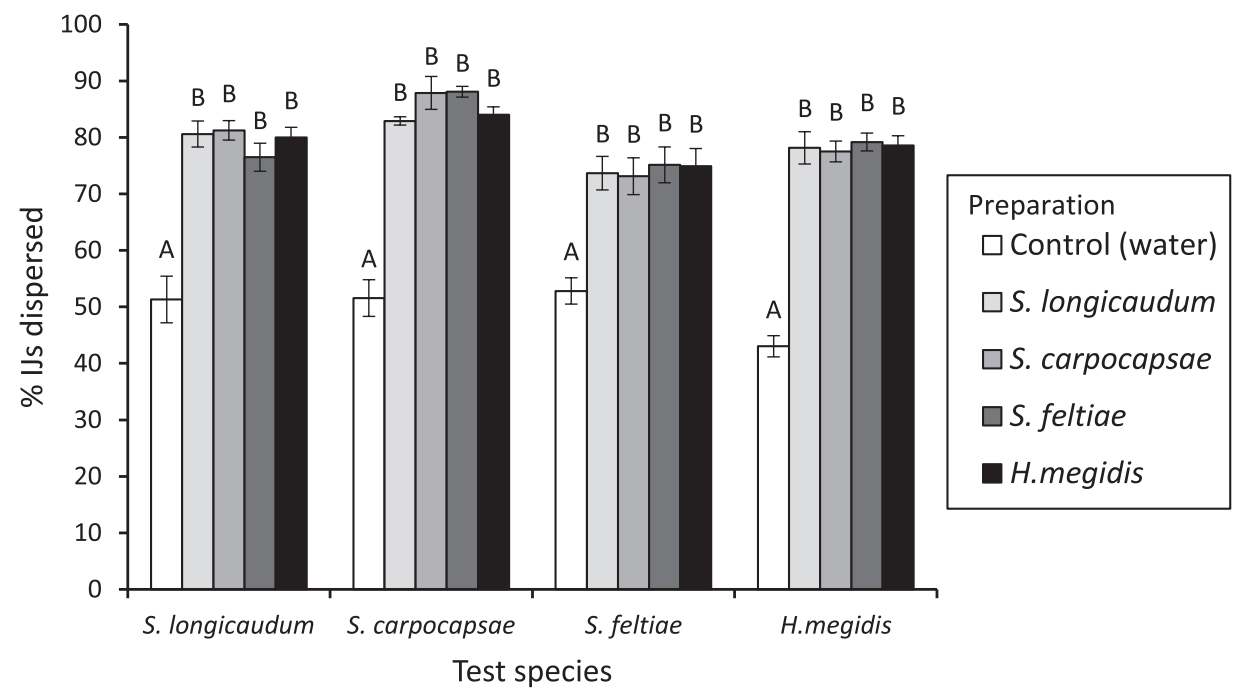

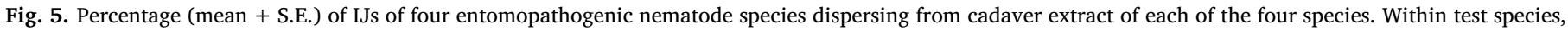
bars which do not share a letter differ significantly.

continued for more than a week. Ascarosides are important in inducing dauer juvenile formation in C. elegans, and it was in this context that their importance as pheromones was first detected (Jeong et al., 2005; Butcher et al., 2007). However, rather little attention has been paid to the production or release of ascarosides by dauer juveniles or the analogous developmentally arrested IJs of parasitic nematodes. Kaplan et al. (2011) did not detect ascarosides in "worm water" conditioned by C. elegans dauers, though small quantities of two ascarosides were found within the dauer bodies, while Choe et al. (2012) detected several ascarosides in worm water from dauers of Caenorhabditis species 7. Ascarosides have also been identified in worm water of IJs of diverse taxonomic and ecological groups including the animal parasite $\mathrm{Nip}$ postrongylus brasiliensis (Choe et al., 2012), various plant parasites (Manosalva et al., 2015; Zhao et al., 2018) and the insect-associated Ocheius carolinensis and Steinernema species (S. carpocapsae, S. scapterisci, S. riobrave and S. glaseri) (Choe et al., 2012)). Our results are the first to show that IJs or dauers continue to release ascarosides to the external medium for longer than $24 \mathrm{~h}$.

Ascr\#9 was the dominant signal detected in the exo-metabolome of the three Steinernema species tested here, with smaller signals for several other ascarosides. This is in line with the findings that the ascaroside blends of various insect-associated nematodes (the entomopathogens Steinernema spp., H. bacteriophora and Oscheius tipuli, the necromenic Pristionchus pacificus, and the beetle-vectored pine wilt nematode Bursaphelenchus xylophilus) (Choe et al. 2012; Zhao et al., 2018) all had high amounts of this ascaroside. Choe et al. (2012) noted that ascaroside biosynthesis patterns appear in part to correlate with lifestyle or ecological niche as well as with phylogeny. Similarly, the plant parasites Meloidogyne spp., Heterodera glycines and Pratylenchus brachyuris all had high expression of ascr\#18 (Manosalva et al., 2015). In our study, the signal for ascr\#18 was higher for $H$. megidis than for the Steinernema spp., consistent with Choe et al.'s (2012) findings of a relatively high signal for ascr\#18 worm water from adult $H$. bacteriophora.

Our experiments show that IJ exometabolome (water conditioned by IJs for 7 days) stimulated dispersal of other, freshly washed IJs. Based on Kaplan et al.'s work there is a strong probability that the dispersal cue of IJ-conditioned water is at least partly due to the ascarosides detected in it, though other unidentified metabolites and excretory products of IJs may also be involved. We also confirm the previous finding (Kaplan et al., 2012; Wu et al., 2018; Oliveira-Hofman et al., 2019) that extract of nematode-infected cadaver promotes dispersal of IJs, and extend this to two other species ( $H$. megidis and $S$. longicaudum). Nitrogenous waste products of nematodes accumulating within the cadaver have been implicated in repulsion of IJs from infected hosts, and in stimulating emergence of IJs developing within the hosts (Shapiro et al., 2000; San-Blas et al., 2008, 2014). Kaplan et al. (2012) demonstrated that ascr\#9 accumulates in cadavers and plays a role in inducing dispersal in $S$. feltiae, but that other components of the cadaver exudate also played a role. Many chemicals are repulsive to IJs in single-agent chemotaxis assays (Lee et al., 2016; Baiocchi et al., 2017). Baiocchi et al. (2017) identified several odorant molecules from Steinernema-infected wax moth larvae that were repulsive to Steinernema IJs. These included prenol and acetyl methyl carbinol, which according to Baiocchi et al. (2017) could conceivably be produced by the nematodes themselves, their symbiotic bacteria, or as a by-product of the decay of the insect cadaver. Thus, the insect cadaver and its extract represent a complex chemical mixture potentially derived not only from the nematodes themselves, but also from a range of bacteria including their symbiont, and products of the cadaver itself. It would be adaptive for IJs to respond to any stimulus, alone or in combination, that signifies a depleted resource, and it is therefore probable that several components of cadaver extract contribute to the dispersal effect on IJs.

Given that any of several different chemicals accumulating in a depleted host cadaver may signify poor resource quality, our finding that IJs of all four species dispersed in response to extract of cadavers infected by each of the other species, as well as their own, is not unexpected. It is perhaps more surprising that the IJs were also stimulated to disperse by water conditioned by IJs of other species as well as their own. This was the case both for the three Steinernema species, and also between Steinernema spp. and the more distantly related $H$. megidis. In this case, the medium is expected to contain a simpler blend of molecules, including ascarosides, but derived from IJs only. The lack of species-specificity means that both cadaver extract and IJ conditioned water can be considered public information, produced by one species but similarly responded to by several species with similar lifestyle (Danchin et al., 2004; Gil et al., 2018). Unlike aggregation and mating signals, there is little advantage to have species-specificity in dispersal cues, and indeed there is an advantage in having common indicators of crowding. Our results support this hypothesis, as do other studies including the observed similarities in ascaroside profiles of Steinernema spp. IJs (Choe et al., 2012), and the experimental evidence showing dispersal of EPN and plant parasites in response $C$. elegans ascaroside 
blends (Kaplan et al., 2012).

The finding that dispersal cues are not species-specific is of potential commercial significance, since it means that a single preparation could be used to stimulate IJs of various EPN species- a significant factor in any possible commercialisation of such an approach. EPN are typically produced in bioreactors, and IJs are cleaned and formulated for distribution, following which they are resuspended in water for application (Ehlers, 2001; Shapiro-Ilan and Gaugler, 2002). The use of insect cadavers to enhance the biocontrol efficacy of EPN in an approach that has been developed in recent decades. Laboratory studies showed that IJs emerging from infected hosts had enhanced dispersal, infectivity and survival compared to IJs applied in water (Shapiro and Glazer, 1996; Shapiro and Lewis, 1999; Perez et al., 2003), and superior efficacy of IJs applied in cadavers was demonstrated in the greenhouse and field (Shapiro-Ilan et al., 2003; Ansari et al., 2009). Application of EPN in cadavers has been advocated as a way of improving field efficacy though this approach faces practical challenges (Dolinski et al., 2015). With the growing evidence that chemical compounds associated with the cadaver stimulate dispersal, as discussed above, and Kaplan et al.'s (2012) demonstration that cadaver exudate stimulated dispersal of $S$. feltiae on agar plate assays, there is potential for addition of dispersalstimulating compounds to tank mix of EPN prior to application, rather than applying cadavers themselves. IJs of three EPN species ( $S$. feltiae, $S$. carpocapsae and $H$. bacteriophora) were stimulated by macerate of cadavers (infected by their own species) to disperse through columns of sand and infect hosts at the bottom (Wu et al., 2018). Subsequently, Oliveira-Hofman et al. (2019) showed that methanol extract of infected cadaver was more effective than cadaver macerate, and that such preparations enhanced the efficacy of EPN against insect pests in greenhouse trials.

In the studies by Wu et al. (2018) and Oliveira-Hofman et al. (2019) it is unclear whether the enhanced infection of insects by treating IJs with cadaver macerate or extract was due to enhanced dispersal of IJs, with host-seeking behaviour remaining unaffected, or whether both untargeted movement (dispersal) and targeted host-finding were impacted. Indeed, it may be difficult to distinguish between the two processes. Behaviours involved in host-finding in EPN have received considerable attention; such studies indicate that IJs may employ active responses including to chemical cues emanating from insects themselves (Grewal et al., 1997; Lewis et al., 2006) and from insect-damaged plant roots (Rasmann and Turlings, 2008; Ali et al., 2012). Less attention has been paid to dispersal as a phenomenon separate from that of host-finding. Dispersal is an essential feature in the life cycle of many animals, serving to move away from depleted resources and/or high numbers of competitors and to avoid inbreeding (Clobert et al., 2001). There is evidence for at least some EPN species, that innate dispersal tendency of IJs is high shortly after they emerge from the cadaver, but declines with time. In $H$. megidis, dispersal declines as infectivity rises, resulting in a characteristic phasing of activity (Dempsey and Griffin, 2002). While the ultimate goal of the $I J$ is to find and invade another host, the first task must be to disperse away from the spent natal cadaver and the densely crowded soil surrounding it. Even species classified as sit-and-wait or ambush foragers, such as $S$. carpocapsae, must disperse from the spent host before or while searching for hosts (Bal et al., 2014). In our long-term storage experiments, there was a decline in dispersal tendency of both $H$. megidis and $S$. carpocapsae over time, irrespective of treatment. In these experiments, IJs provided with clean water on a regular basis to limit the accumulation of IJ exometabolome in the medium dispersed significantly less after some weeks when compared to treatments where the original water remained. This is further evidence that IJs secrete into the medium a compound or compounds that enhance dispersal. Hence the observed level of dispersal (but not virulence) is an interaction of the IJs' endogenous tendency and self-produced exogenous stimuli. Since IJs of entomopathogenic nematodes are routinely stored in aqueous suspension in laboratories (and also between harvesting and formulation in commercial enterprises), this information may help in the interpretation or design of laboratory experiments. The ecological significance is unclear, but there may be circumstances in which a group of IJs remain together for long enough to accumulate sufficient exometabolome in the surrounding soil water film to promote dispersal when conditions favouring movement return.

While we have shown that the exometabolome promotes IJ dispersal, this may not be the primary function. Indeed, since any single chemical could effectively stimulate dispersal (Baiocchi et al., 2017), the complex mix of molecules in the IJ exometabolome would be unnecessarily expensive for this purpose, and hence evolutionarily unstable. There is evidence that EPN IJs exhibit group movement (Fushing et al., 2008; Shapiro-Ilan et al., 2014; Ruan et al., 2018); ascarosides may play a role in intraspecific communication to promote aggregation. There is increasing evidence that ascarosides can be detected by other trophic groups (Hsueh et al., 2013; Manosalva et al., 2015; Zhao et al., 2016, 2018). This may be to the advantage of the nematodes; for example, ascarosides produced by $B$. xylophilus juveniles promoted metamorphosis of their beetle vector and the prevalence of its fungal symbiont (Zhao et al., 2016, 2018). Other soil organisms may "eavesdrop" on nematode communication, to their disadvantage, for example triggering plant defences (Manosalva et al., 2015), and trap formation by nematophagous fungi (Hsueh et al., 2013).

\section{Conclusion}

In conclusion, our study builds on the previous findings of Choe et al. (2012) and Kaplan et al. (2012). Its novelty is three-fold: firstly, in demonstrating that the secretion of ascarosides continues beyond the $6 \mathrm{~h}$ of Choe et al. (2012); secondly, showing that IJ conditioned water (IJ exometabolome) promotes dispersal of IJs, and thirdly, that the dispersal signals of both IJ-conditioned water and EPN-infected cadavers are public information, detected by members of their own and other species.

\section{Acknowledgements}

CJH and PEL were funded by John and Pat Hume scholarships from Maynooth University. Liquid chromatography and high mass accuracy mass spectrometry facilities were funded by Science Foundation Ireland (12/RI/2346 (3)).

\section{Appendix A. Supplementary material}

Supplementary data to this article can be found online at https:// doi.org/10.1016/j.jip.2019.107257.

\section{References}

Ali, J.G., Alborn, H.T., Campos-Herrera, R., Kaplan, F., Duncan, L.W., Rodriguez-Saona, C., Koppenhofer, A.M., Stelinski, L.L., 2012. Subterranean, herbivore-induced plant volatile increases biological control activity of multiple beneficial nematode species in distinct habitats. PLoS One 7, e38146.

Ansari, M.A., Hussain, M., Moens, M., 2009. Formulation and application of entomopathogenic nematode-infected cadavers for control of Hoplia philanthus in turfgrass. Pest Manag. Sci. 65, 367-374.

Baiocchi, T., Lee, G., Choe, D.H., Dillman, A.R., 2017. Host seeking parasitic nematodes use specific odors to assess host resources. Sci. Rep. 7, 6270.

Bal, H.K., Taylor, R.A.J., Grewal, P.S., 2014. Ambush foraging entomopathogenic nematodes employ 'sprinting emigrants' for long distance dispersal in the absence of hosts. J. Nematol. 44, 450-451.

Butcher, R.A., 2017. Decoding chemical communication in nematodes. Nat. Prod. Rep. $34,472-477$.

Butcher, R.A., Fujita, M., Schroeder, F.C., Clardy, J., 2007. Small-molecule pheromones that control dauer development in Caenorhabditis elegans. Nat. Chem. Biol. 3, $420-422$.

Choe, A., von Reuss, S.H., Kogan, D., Gasser, R.B., Platzer, E.G., Schroeder, F.C., Sternberg, P.W., 2012. Ascaroside signaling is widely conserved among nematodes. Curr. Biol. 22, 772-780.

Clobert, E.L., Danchin, E., Dhondt, A.A., Nichols, J.D., 2001. Dispersal. Oxford University Press, Oxford, U.K. 
Danchin, E., Giraldeau, L.A., Valone, T.J., Wagner, R.H., 2004. Public information: From nosy neighbors to cultural evolution. Science 305, 487-491.

Dempsey, C.M., Griffin, C.T., 2002. Phased activity in Heterorhabditis megidis. Parasitology 124, 605-613.

Dolinski, C., Shapiro-Ilan, D., Lewis, E.E., 2015. Insect cadaver applications: pros and cons. In: CamposHerrera, R. (Ed.), Nematode pathogenesis of insects and other pests, pp. 207-229.

Edison, A.S., 2009. Caenorhabditis elegans pheromones regulate multiple complex behaviors. Curr. Opin. Neurobiol. 19, 378-388.

Ehlers, R.-U., 2001. Mass production of entomopathogenic nematodes for plant protection. Appl. Microbiol. Biotechnol. 56, 623-633.

Fushing, H., Zhu, L., Shapiro-Ilan, D.I., Campbell, J.F., Lewis, E.E., 2008. State-space based mass event-history model I: many decision-making agents with one target. Ann. Appl. Stat. 2, 1503-1522.

Gil, M.A., Hein, A.M., Spiegel, O., Baskett, M.L., Sih, A., 2018. Social information links individual behavior to population and community dynamics. Trends Ecol. Evol. 33, 535-548.

Grewal, P.S., Lewis, E.E., Gaugler, R., 1997. Response of infective stage parasites (Nematoda: Steinernematidae) to volatile cues from infected hosts. J. Chem. Ecol. 23, 503-515.

Griffin, C.T., 2015. Behaviour and population dynamics of entomopathogenic nematodes following application. In: Campos-Herrera, R. (Ed.), Nematode Pathogenesis of Insects and Other Pests. Springer, London, pp. 57-95.

Hsueh, Y.P., Mahanti, P., Schroeder, F.C., Sternberg, P.W., 2013. Nematode-trapping fungi eavesdrop on nematode pheromones. Curr. Biol. 23, 83-86.

Jeong, P.Y., Jung, M., Yim, Y.H., Kim, H., Park, M., Hong, E.M., Lee, W., Kim, Y.H., Kim, K., Paik, Y.K., 2005. Chemical structure and biological activity of the Caenorhabditis elegans dauer-inducing pheromone. Nature 433, 541-545.

Kaplan, F., Alborn, H.T., von Reuss, S.H., Ajredini, R., Ali, J.G., Akyazi, F., Stelinski, L.L., Edison, A.S., Schroeder, F.C., Teal, P.E., 2012. Interspecific nematode signals regulate dispersal behavior. PLoS One 7, e38735.

Kaplan, F., Srinivasan, J., Mahanti, P., Ajredini, R., Durak, O., Nimalendran, R., Sternberg, P.W., Teal, P.E.A., Schroeder, F.C., Edison, A.S., Alborn, H.T., 2011. Ascaroside expression in Caenorhabditis elegans is strongly dependent on diet and developmental stage. PLoS One 6, e17804.

Lee, J.H., Dillman, A.R., Hallem, E.A., 2016. Temperature-dependent changes in the hostseeking behaviors of parasitic nematodes. BMC Biol. 14, 36.

Lewis, E.E., Campbell, J., Griffin, C., Kaya, H., Peters, A., 2006. Behavioral ecology of entomopathogenic nematodes. Biol. Control 38, 66-79.

Manosalva, P., Manohar, M., von Reuss, S.H., Chen, S.Y., Koch, A., Kaplan, F., Choe, A., Micikas, R.J., Wang, X.H., Kogel, K.H., Sternberg, P.W., Williamson, V.M., Schroeder, F.C., Klessig, D.F., 2015. Conserved nematode signalling molecules elicit plant defenses and pathogen resistance. Nat. Commun. 6, 7795.

Nadler, S.A., Bolotin, E. Stock, S.P., 2006. Phylogenetic relationships of Steinernema Travassos, 1927 (Nematoda : Cephalobina : Steinernematidae) based on nuclear, mitochondrial and morphological data. Syst. Parasitol. 63, 161-181.

Noguez, J.H., Conner, E.S., Zhou, Y., Ciche, T.A., Ragains, J.R., Butcher, R.A., 2012. A novel ascaroside controls the parasitic life cycle of the entomopathogenic nematode Heterorhabditis bacteriophora. ACS Chem. Biol. 7, 961-966.
Oliveira-Hofman, C., Kaplan, F., Stevens, G., Lewis, E., Wu, S.H., Alborn, H.T., PerretGentil, A., Shapiro-Ilan, D.I., 2019. Pheromone extracts act as boosters for entomopathogenic nematodes efficacy. J. Invertebr. Pathol. 164, 38-42.

Perez, E.E., Lewis, E.E., Shapiro-Ilan, D.I., 2003. Impact of the host cadaver on survival and infectivity of entomopathogenic nematodes (Rhabditida: Steinernematidae and Heterorhabditidae) under desiccating conditions. J. Invertebr. Pathol. 82, 111-118.

Rasmann, S., Turlings, T.C.J., 2008. First insights into specificity of belowground tritrophic interactions. Oikos 117, 362-369.

Ruan, W.B., Shapiro-Ilan, D., Lewis, E.E., Kaplan, F., Alborn, H., Gu, X.H., Schliekelman, P., 2018. Movement patterns in entomopathogenic nematodes: continuous vs. temporal. J. Invertebr. Pathol. 151, 137-143.

San-Blas, E., Gowen, S.R., Pembroke, B., 2008. Steinernema feltiae: Ammonia triggers the emergence of their infective juveniles. Exp. Parasitol. 119, 180-185.

San-Blas, E., Pirela, D., Garcia, D., Portillo, E., 2014. Ammonia concentration at emer gence and its effects on the recovery of different species of entomopathogenic nematodes. Exp. Parasitol. 144, 1-5.

Shapiro-Ilan, D.I., Gaugler, R., 2002. Production technology for entomopathogenic nematodes and their bacterial symbionts. J. Ind. Microbiol. Biotechnol. 28, 137-146.

Shapiro-Ilan, D.I., Lewis, E.E., Schliekelman, P., 2014. Aggregative group behavior in insect parasitic nematode dispersal. Int. J. Parasitol. 44, 49-54.

Shapiro-Ilan, D.I., Lewis, E.E., Tedders, W.L., 2003. Superior efficacy observed in entomopathogenic nematodes applied in infected-host cadavers compared with application in aqueous suspension. J. Invertebr. Pathol. 83, 270-272.

Shapiro, D.I., Glazer, I., 1996. Comparison of entomopathogenic nematode dispersal from infected hosts versus aqueous suspension. Environ. Entomol. 25, 1455-1461.

Shapiro, D.I., Lewis, E.E., 1999. Comparison of entomopathogenic nematode infectivity from infected hosts versus aqueous suspension. Environ. Entomol. 28, 907-911.

Shapiro, D.I., Lewis, E.E., Paramasivam, S., McCoy, C.W., 2000. Nitrogen partitioning in Heterorhabditis bacteriophora-infected hosts and the effects of nitrogen on attraction/ repulsion. J. Invertebr. Pathol. 76, 43-48.

Srinivasan, J., Kaplan, F., Ajredini, R., Zachariah, C., Alborn, H.T., Teal, P.E.A., Malik, R.U., Edison, A.S., Sternberg, P.W., Schroeder, F.C., 2008. A blend of small molecules regulates both mating and development in Caenorhabditis elegans. Nature 454, 1115-U1146.

von Reuss, S.H., 2018. Exploring modular glycolipids involved in nematode chemical communication. Chimia 72, 297-303.

Woodring, J.L., Kaya, H., 1988. Steinernematid and Heterorhabitid Nematodes: A Handbook of Biology and Techniques. Arkansas Agricultural Experiment Station, Fayetteville, Arkansas, USA.

Wu, S.H., Kaplan, F., Lewis, E., Alborn, H.T., Shapiro-Ilan, D.I., 2018. Infected host macerate enhances entomopathogenic nematode movement towards hosts and infectivity in a soil profile. J. Invertebr. Pathol. 159, 141-144.

Zhao, L.L., Ahmad, F., Lu, M., Zhang, W., Wickham, J.D., Sun, J.H., 2018. Ascarosides promote the prevalence of ophiostomatoid fungi and an invasive pathogenic nematode, Bursaphelenchus xylophilus. J. Chem. Ecol. 44, 701-710.

Zhao, L.L., Zhang, X.X., Wei, Y.A., Zhou, J., Zhang, W., Qin, P.J., Chinta, S., Kong, X.B., Liu, Y.P., Yu, H.Y., Hu, S.N., Zou, Z., Butcher, R.A., Sun, J.H., 2016. Ascarosides coordinate the dispersal of a plant-parasitic nematode with the metamorphosis of its vector beetle. Nat. Commun. 7, 12341 . 